\title{
MICORREMEDIAÇÃO DE SOLO IMPACTADO POR RESÍDUOS DE HIDROCARBONETOS
}

FREIRE, Franklin Santos

Biólogo. Mestre em Tecnologia Ambiental (Itep-PE). Professor da disciplina de Ecologia do Curso de Licenciatura em Ciências Biológicas do CESA-PE. Endereço: Rua Capitulino Feitosa, 294, Centro, Arcoverde-PE-Brasil. CEP: 56.506-060.

PEREIRA, Sônia Valéria

Química, Doutora em Botânica (UFRPE). Pesquisadora do Itep-PE. Coordenadora do Mestrado

Profissional em Tecnologia Ambiental.

GATTAI, Graziella de Sá

Bióloga. Mestre em Ciências Biológicas (UFPE).

\begin{abstract}
Resumo
O petróleo e seus derivados são os principais meios de geração de energia para veículos transportadores de matéria-prima e mercadorias produzidas nas regiões desenvolvidas e em desenvolvimento, acentuando os riscos de acidentes por derrames na estocagem, transporte, uso ou descarte. Acontaminação por hidrocarbonetos totais sugere a elevada propensão a mutações e formação de tumores cancerígenos, decorrentes da exposição causada pela contaminação humana por estes produtos. Este trabalho teve como objetivos: a) Investigar, em escala de laboratório, a capacidade degradativa da microbiota autóctone na presença de concentrações variadas de borra de petróleo ( $0 \%, 2,5 \%, 5 \%$ e 7,5\%); b) Isolar fungos tolerantes aos constituintes de petróleo; c) Quantificar e analisar a capacidade de biodegradação do solo através da biomassa microbiana e do quociente metabólico; e d) Definir em laboratório, as condições ideias de biodegradação do petróleo. Foram avaliados parâmetros biológicos (carbono da biomassa microbiana, emissão de $\mathrm{CO}_{2}, q \mathrm{CO}_{2}$ e crescimento fúngico), químicos ( $\mathrm{pH}$, condutividade elétrica - $\mathrm{CE}$-, análise da fertilidade e hidrocarbonetos totais) e físicos (composição física do solo) para análise e comparações. Os resultados obtidos sugerem que a adição de 5\% de borra de petróleo no solo apresentou condição ideal para a biodegradação do contaminante no ambiente. Dos parâmetros avaliados, a emissãode $\mathrm{CO}_{2}$ e o $\mathrm{C}$ microbiano foram considerados os mais indicativos das alterações na atividade microbiana no solo submetido à adição de hidrocarbonetos, evidenciando a possibilidade de uso da micorremediação.
\end{abstract}

PalaVras-ChaVE: Biorremediação; Áreas degradadas; Hidrocarbonetos; Fungos filamentosos.

\begin{abstract}
Oil and its derivatives are the principal means of energy generation for vehicles that transport raw materials and goods produced in developed and developing regions accentuating the risk of accidents by spills in stockpiling, transport, use or discarding. The contamination by total hydrocarbons suggests the elevated propension to mutations and to the formation of carcinogenic tumors, as a consequence of the exposure to human contamination by these products. This work had as aims: a) To investigate, in a laboratorial scale, the degrading capacityof autochthonous microbiota in the presence of differing concentrations of hydrocarbons $(0 \%, 2,5 \%, 5 \%$ e 7,5\%); b) To isolate fungi tolerant to the contaminant; c) To quantify and analyze the biodegradation capacity of soil through the microbial biomass and metabolic quotient; and d) To set, in laboratory, ideal conditions of biodegradation of the xenobiotic compound. Some parameters of microbial activity have been evaluated, such as: biological (Carbon of microbial biomass, $\mathrm{CO}_{2}, q \mathrm{CO}_{2}$ emission, and fungi growth), chemical ( $\mathrm{pH}$, electrical conductivity - EC-, analysis of fertility and total hydrocarbons) and physical (physical composition of the soil) for analysis and comparisons. The obtained results suggest that the adding of $5 \%$ of waste oil in the ground provided ideal condition for the biodegradation of
\end{abstract}


the contaminant in the environment. From the evaluated parameters, the emission of $\mathrm{CO}_{2}$ and microbial $\mathrm{C}$ were considered more indicative of changes in soil microbial activity subject to the addition of hydrocarbons, confirming the possibility of microremediation use.

KeYwords: Bioremediation; Degrading areas; Hydrocarbons; Filamentary fungi.

\section{INTRODUÇÃo}

Nos dias atuais, a exploração desenfreada das fontes não renováveis de energia, e mais precisamente do petróleo e seus derivados, tem exigido um aumento na produção, armazenamento e distribuição de produtos gerados para as diferentes áreas populacionais de produção industrial. Porém, inerentes a essas atividades estão os riscos de poluição ambiental, quando são realizadas sem os devidos procedimentos preventivos.

A história de empresas petrolíferas no mundo é carreada por catástrofes no campo da mineração desse precioso produto e por acidentes oriundos de derrames com repercussão mundial: em 1978, mais de 200 mil toneladas de óleo foram derramados na costa da França pelo acidente com o navio Amoco Cadiz; em 1989, 40 mil toneladas vazaram do navio Exxon Valdez no litoral do Alasca; em 1991, o incêndio do navio Haven, na costa da Itália, ocasionou o derrame de 140 mil toneladas de óleo; em 1991, na Guerra do Golfo, vários poços de petróleo foram sabotados e explodidos ocasionando um desastre na ordem de mais de 820 mil toneladas, contaminando vasta região do Kuwait.

No Brasil, vários acidentes enumeram as estatísticas, mais especificamente com o óleo diesel, que é um dos principais derivados utilizados pela malha de transporte rodoviário. Nos últimos anos, ocorreram vários acidentes: com o trem da Companhia América Latina Logística (ALL), que carregava 60 mil litros de óleo diesel, despejando grande parte para o córrego próximo a Fernandez Pinheiro no Paraná (2000); o rompimento de duto da Petrobrás provocou vazamento de 4 mil litros de óleo diesel no Córrego Caninana, afluente do Rio
Nhundiaquara no Amazonas, contaminando a flora e a fauna de toda região (2001); o descarrilamento do trem da Ferrovia Novoeste, que despejou 35 mil litros de óleo diesel em uma área de preservação ambiental de Campo Grande, Mato Grosso do Sul(2001); e o vazamento de óleo diesel em um tanque operado pela Shell no bairro Rancho Grande, São Paulo, contaminou o solo e, por consequência, o lençol freático e o manancial da cidade (2002).

Esses acidentes serviram para nortear estudos visando ao desenvolvimento de tecnologias voltadas para o controle e a recuperação de áreas degradadas, entre elas a biorremediação.

A biorremediação é o uso de microrganismos em processos de degradação de compostos poluentes no solo ou da água e sua transformação em outros menos recalcitrantes (BENTO, 2003; JACQUES et al. 2007). Desde 1946, os microbiologistas isolam e identificam microorganismos capazes de degradar o petróleo, relacionando aqueles que conseguem utilizar os elementos degradados como fonte de carbono e transformando-os em biomassa, mesmo sabendo que os derrames de petróleo e derivados não eram considerados um problema ambiental significativo (ZOBELL, 1946).

Dentre as técnicas utilizadas em projetos de remediação ambiental, uma das que apresentam considerável avanço quando aplicada é a micorremediação, ou seja, o uso de fungos na biodegradação de solo contaminado por compostos xenobióticos (MORENO et al., 2004). Os fungos realizam um trabalho considerado importante na natureza, degradando de celulose até polímeros. $\mathrm{Na}$ atualidade, o uso de fungos em relação ao de bactérias para fim de biodegradação é muito raro, principalmente empaíses como o Brasil, onde indústrias petroquímicas usam a técnica de landfarming para o tratamento de resíduos sólidos (JACQUES et al., 2007).

As pesquisas desenvolvidas até o momento procuram responder às várias questões envolvendo a aplicação da técnica da biorremediação: 1. Que tipos de componentes presentes no petróleo são biodegradáveis?2. Quais fatores ambientais limitame 
estimulam a degradação? e 3. Quais as populações de microrganismos capazes de degradar e qual a sua distribuição no ambiente? Até o momento, o estudo e o uso da micorremediação como meio empregado para a biodegradação ainda são inexpressíveis no Brasil. Nesse sentido, são necessários estudos que indiquem metodologias apropriadas que permitam avaliar o impacto da presença de hidrocarbonetos na atividade microbiana do solo.

\section{LOCAL DE ESTUDO}

A área selecionada para coleta das amostras está assentada sobre sedimentos recentes e sub-recentes por depósitos da chamada Planície de Recife. Esta planície está situada sobre depósitos quartenários compostos por areias e argilas de origem fluviomarinha, provenientes do Grupo Barreiras e de origem caulínitica, com influência direta da deposição de sedimentos da foz dos rios Capibaribe e Beberibe. Essa área de topografia plana (170 mil m²), denominada Área do Brum, é integrante da região estuarina dos rios Capibaribe e Beberibe, tendo sido ocupada por antigas instalações de recebimento, estocagem e distribuição de petróleo e derivados.

Ainda podemos identificar, dependendo da profundidade, uma modificação das camadas de material litológico, até $1,5 \mathrm{~m}$, predominando superficialmente aterros constituídos de areias médias de diversas colorações, entre 1,5 m e $10 \mathrm{~m}$ de argilas siltosas de coloração marrom, ocre e cinza.

A hidrogeologia da área apresenta dois aquíferos (cristalino e de camadas sedimentares), deixando evidentes situações bem distintas quanto à movimentação do lençol freático. Em maré baixa, o deslocamento obedece ao sentido sudoeste para nordeste, em direção ao rio Beberibe. No entanto, na maré alta, a inversão do fluxo ocorre para o interior da ilha, em sentido ao Oceano Atlântico.

A seleção da área destinada à coleta do solo foi baseada em diagnóstico previamente realizado pela empresa GEO CSD, onde foi verificada a presença de derivados de petróleo no subsolo.

As tubulações responsáveis pela distribuição dos derivados de petróleo são na sua maioria subterrâneas, sendo os tanques assentados sobre bases de concreto sem pavimentação adequada (GEO CSD, 2002).

$\mathrm{Na}$ área selecionada para coleta, durante a década de 80 , foram realizadas obras de manutenção e reforma portuária, identificando-se a presença subterrânea de hidrocarbonetos no lençol freático, sendo aplicadas apenas medidas mitigadoras, impedindo sua chegada ao nível do mar e possível acidente ambiental mais sério.

Das 11 áreas antigas utilizadas para armazenamento e distribuição dos derivados de petróleo, somente 2 ainda mantêma atividade (BR Distribuidora e Ipiranga). O solo retirado por escavação das áreas contaminadas por óleo estava acondicionado em "bags" e disposto em pátio de estocagem do Porto, sob a responsabilidade das empresas geradoras do resíduo.

\section{DeSENHO EXPERIMENTAL}

As amostras de solo nativo ( $\mathrm{SN}$ ) e de solo contaminado com borra de derivados de petróleo $(\mathrm{S}+\mathrm{B})$ foram coletadas no mês de agosto de 2006, em uma antiga área de estocagem de derivados de petróleo da BR Distribuidora. As amostras de $\mathrm{SN}$ foram coletadas em uma área intacta (0-20 $\mathrm{cm}$ de profundidade) do Porto, onde nunca houve escavação nem deposição de qualquer material que contenha hidrocarbonetos. As amostras de Borra (B) foram coletadas do material armazenados em "bags" localizados na antiga área de estocagem do Porto do Recife.

As amostras de solo nativo (SN) utilizadas no experimento receberam adição de borra nas concentrações de 2,5, 5,0 e 7,5\%, sendo estabelecido como testemunha o tratamento de $0 \%$.

Recipientes de vidro (11) contendo $20 \mathrm{~g}$ de solo foram preparados de forma a permitir que a cada semana amostras em triplicata dos tratamentos $(0 \%$, $2,5 \%, 5 \%$ e $7,5 \%$ ) fossem analisadas. No total foram montados 12 recipientes, mantidos fechados e incubados por um período de 56 dias.

Esse sistema foi preparado para permitir a realização do ensaio, em escala de laboratório, visando à verificação de alterações na microbiota do solo 
através da análise da respirometria, biomassa microbiana, número de colônias fúngicas, bem como a análise de parâmetros físico-químicos do solo afetado.

\section{Análise do SOlo}

A análise de fertilidade foi realizada no Laboratório de Solo da empresa Agrolab e as análises química, bioquímica e microbiológica foram realizadas nos seguintes Laboratórios da Associação Instituto de Tecnologia de Pernambuco (Itep): Laboratório de Tecnologia Ambiental, Laboratório de Microbiologia e Físico-Química de Alimentos e Laboratório de Fluidos.

Os parâmetros estudados estão descritos a seguir:

\section{Condutividade elétrica - CE}

As suspensões (1 solo: 2 água) de solo foram preparadas pesando-se $10 \mathrm{~g}$ da amostra e adicionados a $20 \mathrm{ml}$ de água destilada. Após 24 horas, realizou-se a medição da $\mathrm{CE}$ no sobrenadante (FRIGHETTO, 2000).

\section{pH}

$\mathrm{O} \mathrm{pH}$ foi determinado eletronicamente, por meio de eletrodo combinado, imerso em suspensão solo:líquido (1 solo: 2 água). Foram pesados $10 \mathrm{~g}$ de solo em um béquer de $50 \mathrm{ml}$, adicionando-se $25 \mathrm{ml}$ de água deionizada. Foi deixado agitar por 20 minutos, esperando-se em seguida a decantação por 30 minutos, medindo o pH do sobrenadante por 2 minutos. Foi utilizado um pHmetro de bancada Pack pH 21 para medição do potencial (FRIGHETTO, 2000).

\section{Respirometria}

O método utilizado se baseia na absorção estática (por difusão) do $\mathrm{CO}_{2}$ desprendido do solo por uma solução alcalina $(\mathrm{KOH} 0,5 \mathrm{~N})$, em um recipiente fechado e incubado por um período de 56 dias (GRISI, 1984).

As amostras de solo foram pesadas (20 g cada) em copos plásticos em número de cinco repetições cada. Uma lâmina de água destilada foi colocada para manter a umidade nos potes de vidro, sendo depositados em seguida as amostras pesadas e um recipiente plástico contendo $10 \mathrm{ml}$ de $\mathrm{KOH} 0,5 \mathrm{~N}$. Os recipientes de 11 foram tampados e vedados com parafilm para não permitir a entrada nem a saída de ar no interior dos mesmos.

A cada intervalo de sete dias, os recipientes foram abertos e as soluções de $\mathrm{KOH} 0,5 \mathrm{~N}$, transferidas para Erlenmeyers e procedida a titulação com $\mathrm{HCl} 0,1 \mathrm{~N}$, utilizando fenolftaleína e metilorange como indicadores.

\section{Biomassa microbiana}

O método utilizado foi o de fumigação-extração (VANCE et al, 1987), seguindo o princípio do aumento dos teores de $\mathrm{Ce} \mathrm{N}$, extraíveis por $\mathrm{K}_{2} \mathrm{SO}_{4} \mathrm{e}$ oxidados com dicromato de potássio $\left(\mathrm{K}_{2} \mathrm{Cr}_{2} \mathrm{O}_{7}\right)$. Essas substâncias, liberadas após fumigação do solo com clorofórmio, estão relacionadas aos constituintes celulares liberados das células microbianas após rompimento da membrana submetida a uma atmosfera de solvente lipolítico.

O método prevê as etapas de fumigação com clorofórmio, extração com sulfato de potássio e digestão ácida com dicromato de potássio do $\mathrm{C}$ microbiano. No processo de fumigação, as amostras de solo em estudo ( $4 \mathrm{~g}$ ), contidas em recipientes com tampa, receberam $0,2 \mathrm{ml}$ de clorofórmio e mantidas em repouso por 20 minutos. Em seguida, as amostras foram transferidas para Erlemneyer de $250 \mathrm{ml}$, e adicionados $40 \mathrm{ml}$ de sulfato de potássio. Para efetuar a digestão das amostras, alíquotas de $8,0 \mathrm{ml}$ do extrato foram transferidas para tubos, adicionados $2,0 \mathrm{ml} \mathrm{de}$ $\mathrm{K}_{2} \mathrm{Cr}_{2} \mathrm{O}_{7}, 5,0 \mathrm{ml}$ de ácido fosfórico concentrado e $10 \mathrm{ml}$ de ácido sulfúrico concentrado e em seguida submetidos a aquecimento por 30 minutos, a uma temperatura de $100^{\circ} \mathrm{C}$. Após resfriamento, as amostras foram tituladas com sulfato ferroso amoniacal $(0,333 \mathrm{~N})$, utilizando como indicador a ferroína. O mesmo procedimento foi utilizado para o solo não fumigado, excetuando-se a etapa de fumigação com clorofórmio.

O mesmo procedimento foi utilizado para o solo fumigado, acrescentando a presença de $0,2 \mathrm{ml}$ de clorofórmio. Os extratos, depois de diluídos, foram 
titulados com sulfato ferroso amoniacal $(0,333 \mathrm{~N})$ e ferroína como indicador.

\section{Quociente metabólico- $q \mathrm{CO}_{2}$}

O Quociente Metabólico $\left(q \mathrm{CO}_{2}\right)$, índice usado para avaliar as condições metabólicas da biomassa microbiana, é calculado pela relação entre a respiração basal e o $\mathrm{C}$ da biomassa microbiana (ANDERSON \& DOMSCH, 1993).

O cálculo do $q \mathrm{CO}_{2}$ foi realizado por meio da relação entre o $\mathrm{CO}_{2}$ acumulado $\left(\mu \mathrm{gC}-\mathrm{CO}_{2} \cdot \mathrm{g} \mathrm{solo}^{-1}\right)$ e o $\mathrm{C}$ da biomassa microbiana $\left(\mu \mathrm{gC}\right.$. g solo $\left.{ }^{-1}\right)$.

\section{Crescimento de colônias fúngicas}

Para isolamento dos fungos filamentosos tolerantes aos constituintes dos petróleos, foram pesados $10 \mathrm{~g}$ de solo e diluídos em $90 \mathrm{ml}$ de água destilada, correspondendo a uma suspensão 1:10. Nas posteriores diluições, foi transferido $1 \mathrm{ml}$ das suspensões para tubos de ensaio contendo $9 \mathrm{ml}$ de água destilada até a concentração de $10^{-3}$. Para cada diluição, foi tomado, em triplicata, 1,0 ml da suspensão de solo e inoculado em placas de Petri contendo meio Batata-Dextrose-Ágar (BDA), com auxílio de alça de Drigalski. As placas foram incubadas em temperatura ambiente durante sete dias, sendo os resultados expressos em Unidades Formadoras de Colônias $\left(\mathrm{UFC} \mathrm{g} \mathrm{solo}{ }^{-1}\right)$.

\section{Hidrocarbonetos totais de petróleo}

A análise da presença de hidrocarbonetos totais de petróleo (HTP) foi realizada no Laboratório de Fluidos do Itep (método de cromatografia gasosa) e no Laboratório de Microbiologia e Físico-Química de Alimentos (LMFQA) .

\section{Resultados E Discussão \\ Análise de solo}

A Tabela 1 descreve a análise física do solo estudado, sendo $\mathrm{SN}$ o solo nativo e $\mathrm{S}+\mathrm{B}$ o solo contaminado.

A Tabela 2 descreve a análise química do solo nativo e contaminado (solo coletado para o experimento sem diluição).

Tabela 1 - Análise física do solo nativo e contaminado.

\begin{tabular}{|l|c|c|c|c|c|c|}
\hline Solo & $\begin{array}{c}\text { Densidade } \\
\text { do solo } \\
\left(\mathrm{g} / \mathrm{cm}^{3}\right)\end{array}$ & $\begin{array}{c}\text { Areia } \\
\text { Grossa } \\
\mathrm{g} / \mathrm{kg}\end{array}$ & $\begin{array}{c}\text { Areia } \\
\text { Fina } \\
\mathrm{g} / \mathrm{kg}\end{array}$ & $\begin{array}{c}\text { Silte } \\
\mathrm{g} / \mathrm{kg}\end{array}$ & $\begin{array}{c}\text { Argila } \\
\mathrm{g} / \mathrm{kg}\end{array}$ & $\begin{array}{c}\text { Classificação } \\
\text { Textural }\end{array}$ \\
\hline $\mathrm{SN}$ & 1,65 & 853 & 101 & 26 & 20 & Arenoso - AR \\
\hline $\mathrm{S}+\mathrm{B}$ & 1,65 & 853 & 101 & 26 & 20 & Arenoso - AR \\
\hline
\end{tabular}

Tabela 2 -Análise química do solo nativo e contaminado.

\begin{tabular}{|c|c|c|c|c|c|c|}
\hline Solo & $\begin{array}{c}\text { Carbono } \\
\mathrm{g} / \mathrm{kg}\end{array}$ & $\begin{array}{c}\text { Nitrogênio } \\
\mathrm{g} / \mathrm{kg}\end{array}$ & $\begin{array}{c}\text { Relação } \\
\mathrm{C} / \mathrm{N}\end{array}$ & $\begin{array}{c}\text { Matéria Orgânica } \\
\mathrm{g} / \mathrm{kg}\end{array}$ & $\begin{array}{c}\mathrm{pH} \\
(1: 2)\end{array}$ & $\begin{array}{c}\text { Fósforo } \\
\text { Assimilável } \\
\mathrm{mg} / \mathrm{kg}\end{array}$ \\
\hline $\mathrm{SN}$ & 1,19 & 0,2 & 5,50 & 1,90 & 7,9 & 16 \\
\hline $\mathrm{S}+\mathrm{B}$ & 2,28 & 0,3 & 7,33 & 3,79 & 7,7 & 28 \\
\hline
\end{tabular}


Condutividade elétrica - CE

A Tabela 3 descreve os valores relativos à condutividade elétrica (CE) do solo, evidenciando pequena diferença entre os valores encontrados nas concentrações do experimento.

Tabela 3 - Valores médios de condutividade elétrica (CE) do solo nativo e contaminado, submetidos a diferentes concentrações de hidrocarbonetos $(0 ; 2,5 ; 5$ e $7,5 \%)$.

\begin{tabular}{|l|c|c|c|c|}
\hline Tratamentos & $0 \%$ & $2,5 \%$ & $5,0 \%$ & $7,5 \%$ \\
\hline $\mathrm{CE}(\mu \mathrm{s} / \mathrm{m})$ & 98,3 & 90,85 & 91,85 & 94,6 \\
\hline
\end{tabular}

\section{pH}

Segundo Canals (2005), o pH considerado ótimo para a biodegradação de compostos xenobióticos está entre 6 e 8 em temperatura ambiente $\left(20^{\circ}-30^{\circ} \mathrm{C}\right)$. Uma variação acentuada no $\mathrm{pH}$ pode afetar de forma considerável a microbiota e a velocidade de degradação dos compostos. Essa reação se apresenta de forma mais específica para os cátions que são mais solúveis em pH ácido e para os ânions solúveis em $\mathrm{pH}$ alcalino.
Conforme apresentado na Figura 1, foi possível verificar variação do $\mathrm{pH}(7,77-8,30)$ das amostras submetidas à contaminação por hidrocarbonetos durante os 56 dias do experimento. Estudos realizados por Dibble e Bartha (1979) sugerem que, sob condição de $\mathrm{pH}$ neutro, o processo de degradação de compostos recalcitrantes é mais eficiente.

Os solos contaminados na concentração de 2,5 e $5 \%$ apresentaram a menor taxa de variação do $\mathrm{pH}$ entre os 56 dias de experimento.

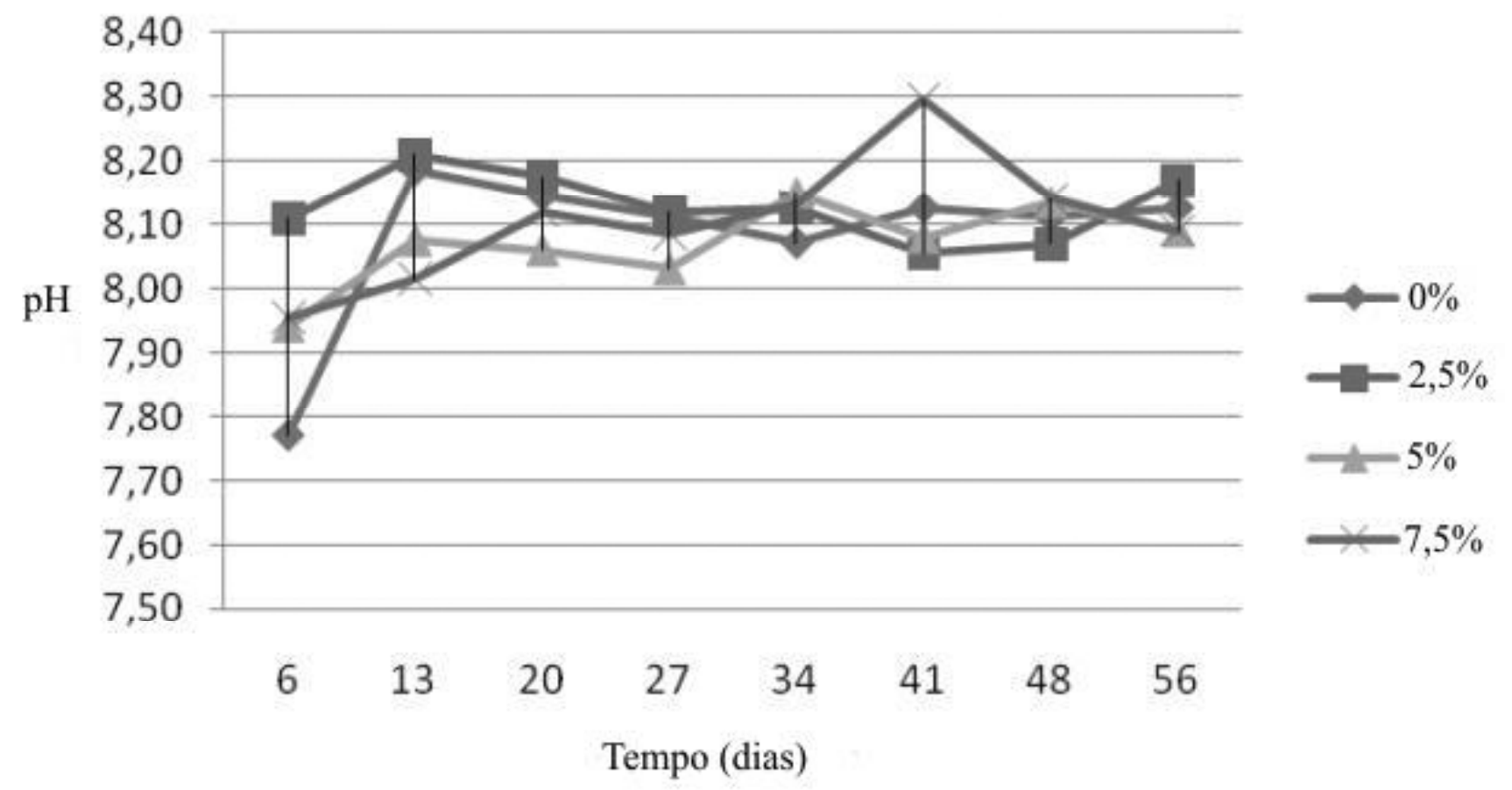

Figura 1 - Variação do pH. 


\section{Respirometria}

Com relação à emissão de $\mathrm{CO}_{2}$ do solo, foi verificado aumento a partir do $20 .^{\circ}$ dia de experimento, em função da adição de doses de hidrocarbonetos. Essa alteração sugere que a atividade microbiana do solo foi estimulada pela presença do hidrocarboneto, promovendo a degradação e, consequentemente, aumento na emissão de $\mathrm{CO}_{2}$. Foi evidenciada uma adaptação da microbiota durante a primeira semana de análise do experimento, seguida de uma curva de crescimento exponencial da população, atingindo uma terceira fase, esta de estacionamento (Figura 2), o que comprova a rápida adaptação dos microrganismos presentes no $\mathrm{SC}$ nas suas diversas concentrações $(0 \%, 2,5 \%, 5 \%$ e $7,5 \%$ ).

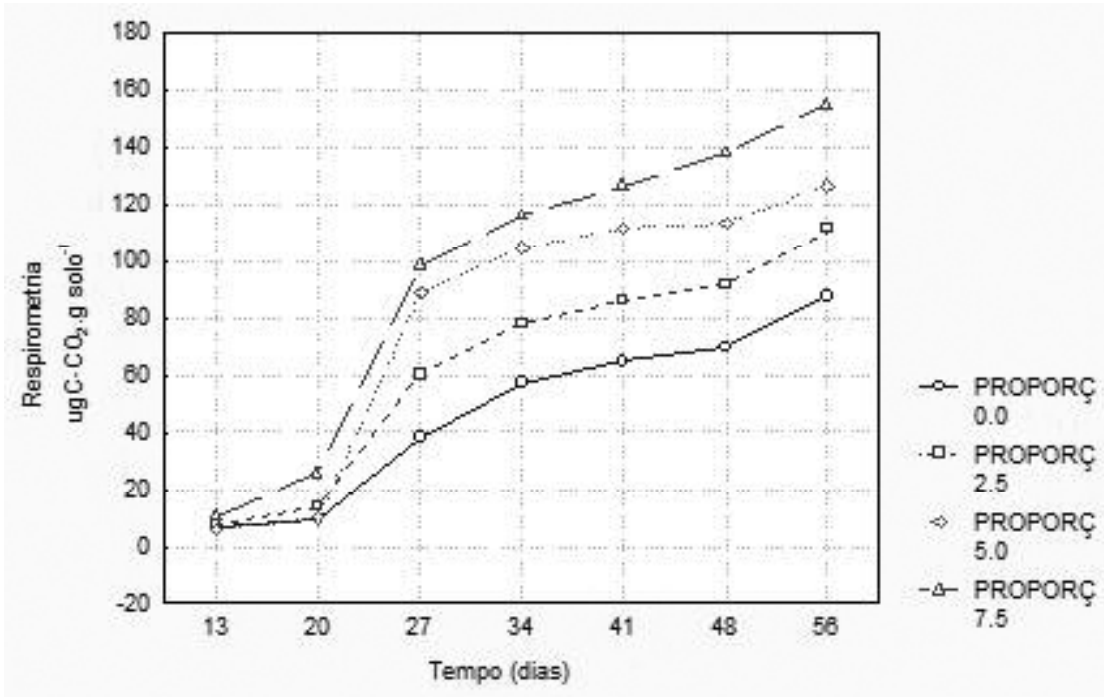

Figura 2 $-\mathrm{F}(18,84)=3,21 ; \mathrm{p}<, 0002$

\section{Biomassa microbiana}

Os resultados indicam maior concentração média de carbono microbiano no solo contaminado com hidrocarbonetos, com a concentração de 5\%, durante o tempo de experimento (56 dias) (Figura 3), em relação aos outros tratamentos. Na concentração de 2,5\% de hidrocarbonetos, não foi observada diferença em relação ao solo nativo quanto à presença de carbono microbiano, mantendo-se constante durante o período de incubação.

O solo recebendo 7,5\% de contaminante apresenta valores superiores ao solo nativo e ao contaminado com 2,5\%, mas inferior à concentração de 5\%, sugerindo que a alta porcentagem adicionada de contaminante pode afetar a comunidade microbiana do solo. 


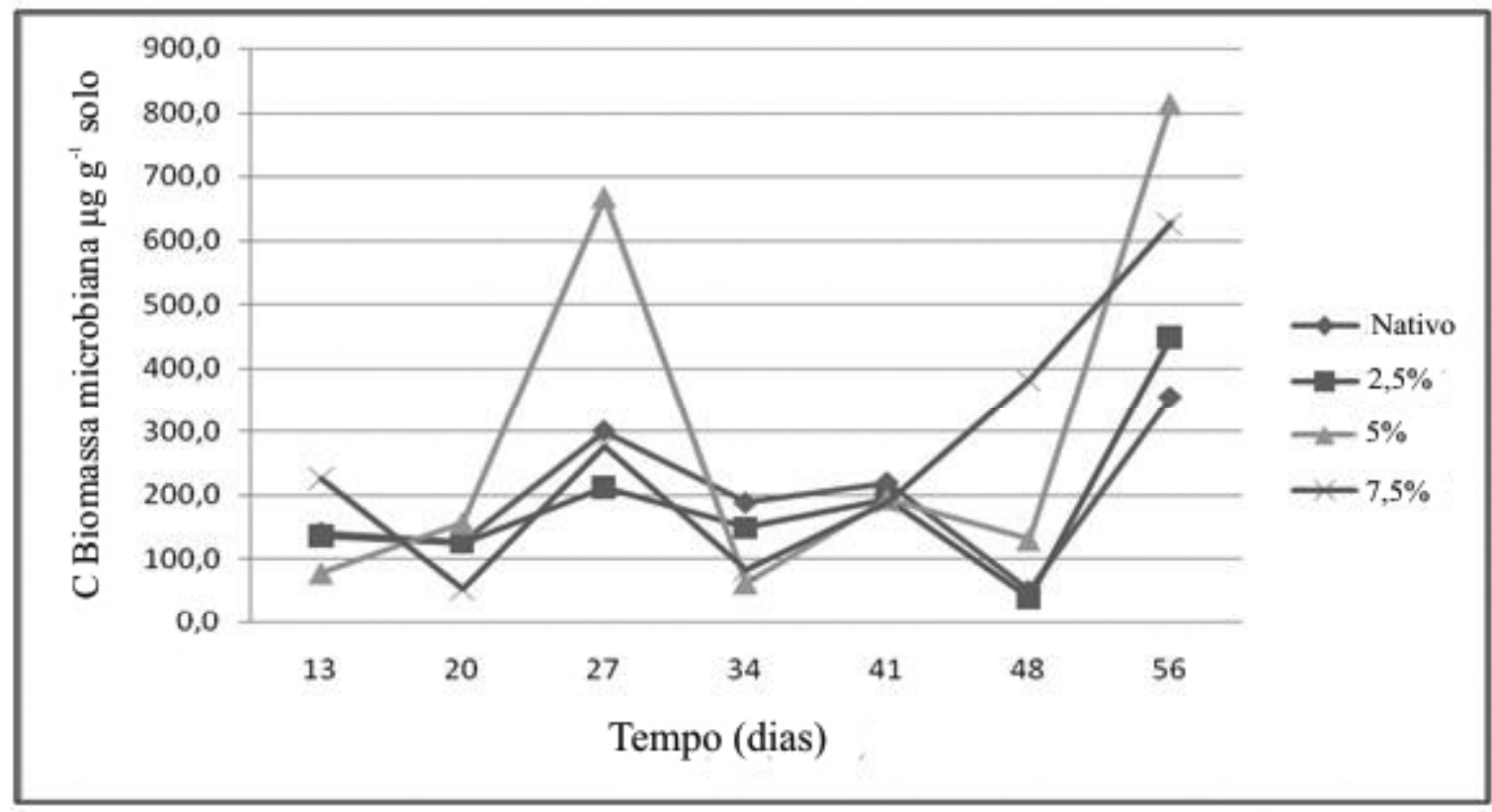

Figura 3 - Concentração Média do Carbono Microbiano.

Quociente metabólico- $q \mathrm{CO}_{2}$

Segundo Paula et al. (2006), os valores mais elevados de $q \mathrm{CO}_{2}$ podem indicar um estresse fisiológico na comunidade microbiana. Foi observado que o solo contaminado com a concentração de 7,5\% apresenta o valor de coeficiente metabólico superior aos outros tratamentos, caracterizando estresse fisiológico da microbiota presente, o que não se verifica até o $27 .^{\circ}$ dia, evidenciando período de adaptação. Foi observado comportamento similar entre as diversas concentrações no $56 .^{\circ}$ dia de experimento (Figura 4).

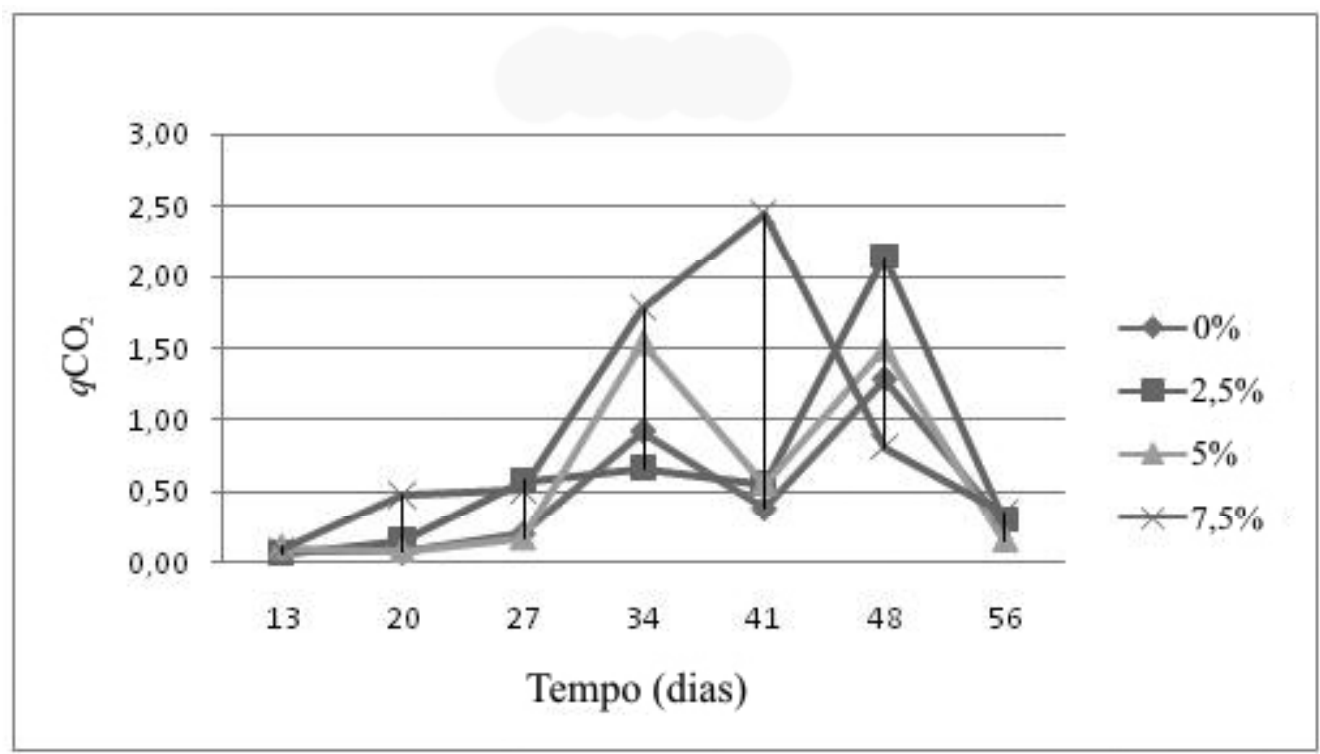

Figura 4 - Média de $q \mathrm{CO}_{2}$. 


\section{Unidade Formadora de Colônia - UFC}

A contagem de colônias fúngicas (UFC) não é considerada uma estimativa confiável, em razão principalmente das limitações de cultivo de microorganismos em condições de laboratório. No entanto, este parâmetro pode sugerir alterações na composição da comunidade fúngica, evidenciadas pelo número e diversidades de colônias formadas. Neste estudo, foiobservado que no solo nativo (concentração de $0 \%$ ), a microbiota permaneceu constante durante o período de 56 dias. Por outro lado, as amostras que receberam doses de hidrocarbonetos nas concentrações de 2,5\% e 7,5\% apresentaram declínio no número de colônias após a $1 .^{\mathrm{a}}$ semana de incubação, sendo observado crescimento a partir da $2{ }^{a}$ semana. No tratamento referente à concentração de 5\%, foi possível constatar maior crescimento fúngico em relação aos outros tratamentos estudados no $20^{\circ}$ e $34 .^{\circ}$ dia de experimento, não sendo observado nos demais tempos individuais (Figura 5).

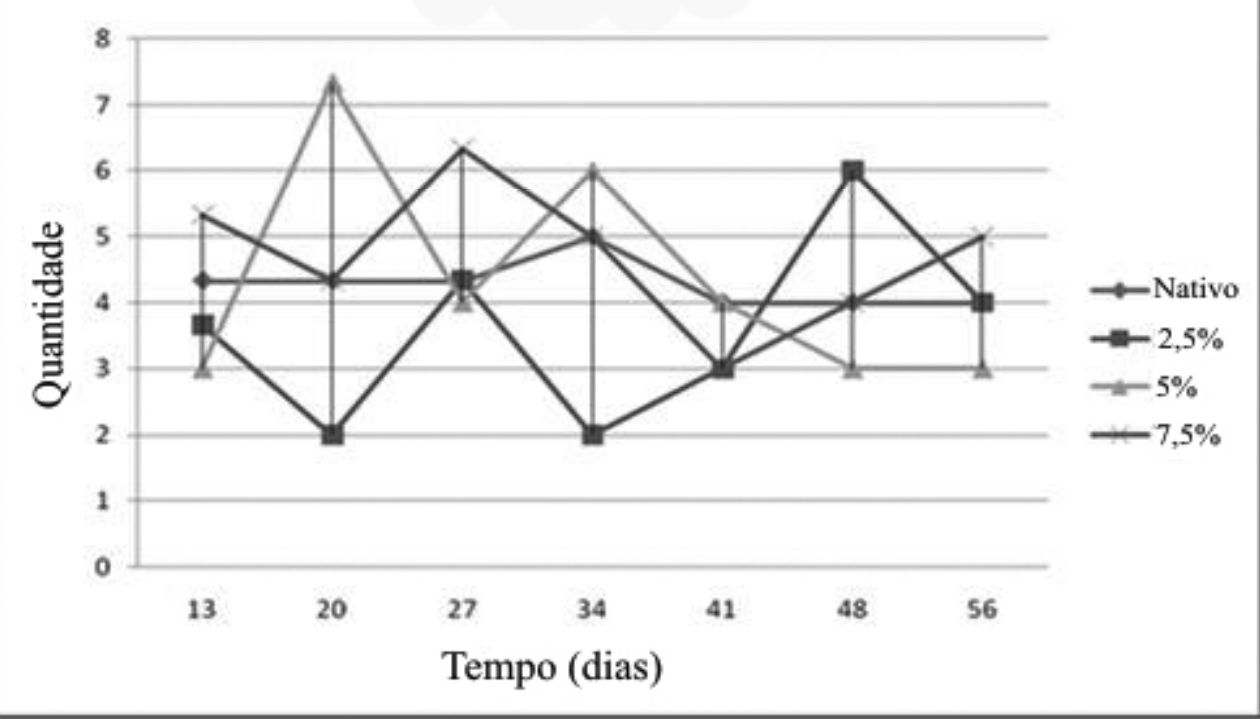

Figura 5 - Média de UFC.

\section{Hidrocarboneto total de petróleo}

$\mathrm{Na}$ análise quantitativa de hidrocarbonetos totais de petróleo (1000 ppm e $5000 \mathrm{ppm}$ ) pelo de método de cromatografia gasosa, usando hexano como diluente em detector de ionização de chama, não foi possível detectar a presença deste tipo de composto. $\mathrm{O}$ resultado pode estar relacionado ao fato de que o material tem principalmente hidrocarbonetos de cadeia longa, o que inviabilizou a quantificação por esta técnica. No entanto, pela quantificação pelo método de extração com hexano (STANDARD METHODS FOR THE EXAMINATION OF WATER AND WASTEWATER, 1998), foi possível evidenciar a presença de hidrocarboneto total nas amostras de solo com as respectivas concentrações (Tabela 4). Não foi possível quantificar de forma individual os compostos presentes na borra, devido à diversidade do material coletado no local de depósito.

Tabela 4 - Valores médios de hidrocarbonetos totais presentes na borra e nas amostras de solo submetidas a diferentes concentrações do contaminante $(2,5 ; 5$ e 7,5\%) no início do experimento.

\begin{tabular}{|c|c|c|c|c|}
\hline \multirow{2}{*}{ Solos/tratamentos } & Resíduo (borra) & $2,5 \%$ & $5,0 \%$ & $7,5 \%$ \\
\cline { 2 - 5 } & 1,39 & 0,18 & 0,24 & 0,30 \\
\hline
\end{tabular}




\section{Matéria orgânica}

Nas análises das amostras de solo contaminado e das respectivas concentrações utilizadas $(0 \%$, 2,5\% 5\% e 7,5\%), foi possível observar (Tabela 5) um aumento da concentração de matéria orgânica presente no solo contaminado (Borra) em função da adição do contaminante. Estes valores apresentados de MO sugerem que o aumento da emissão de $\mathrm{CO}_{2}$, observado durante o experimento, pode estar relacionado ao produto da reação de oxidação do carbono, oriundo do contaminante adicionado no solo.

Tabela 5 - Valores médios do teor de matéria orgânica nas amostras de solo submetidas a diferentes concentrações de hidrocarbonetos $(0 ; 2,5 ; 5$ e $7,5 \%)$.

\begin{tabular}{|c|c|c|c|c|c|}
\hline \multirow{2}{*}{ Solos/tratamentos } & $\begin{array}{c}\text { Resíduo } \\
\text { (borra) }\end{array}$ & $0 \%$ & $2,5 \%$ & $5,0 \%$ & $7,5 \%$ \\
\cline { 2 - 6 } & 2,71 & 0,60 & 0,81 & 1,02 & 1,20 \\
\hline
\end{tabular}

A matéria orgânica do solo (MOS) desempenha um papel fundamental nos processos químicos, físicos e biológicos do solo. Nos processos de reabilitação de áreas impactadas, o aporte de MOS representa o ponto de partida, influenciando diversos atributos do solo.

\section{Conclusões}

Com base no trabalho realizado, concluiu-se que:

$\mathrm{O}$ aumento da emissão de $\mathrm{CO}_{2}$ do solo em função da adição de doses crescentes de hidrocarbonetos indica habilidade de adaptação da microbiota em condições do estudo;

A estimativa do carbono microbiano indica que o tratamento de $5 \%$ de hidrocarbonetos no solo foi o mais apropriado para as condições estabelecidas, sendo esta concentração do contaminante considerada ideal para a biorremediação em experimento laboratorial;

Os valores de coeficientes metabólicos $\left(q \mathrm{CO}_{2}\right)$ sugerem que a concentração de 7,5\% é o limite máximo de biodegradação de borra de petróleo no solo, nas condições de estudo;

A capacidade de crescimento fúngico no solo contaminado com hidrocarbonetos foi comprovada pelo cultivo emmeio de cultura, em condições de laboratório;

$\mathrm{O}$ pH do solo controle ( $\mathrm{SN}$ ) e do solo contaminado (SC) não sofre variação considerável, mantendo-se dentro dos padrões relatados em diversos trabalhos sobre biorremediação.

\section{Agradecimentos}

Nossos agradecimentos são dirigidos aos componentes do Laboratório de Tecnologia Ambiental do Itep e do LMFQA, na pessoa do sr. Edson Silva, bem como, a administração do Porto do Recife (PE), pela abertura da área de estudo.

\section{REFERÊNCIAS}

ANDERSON, J. P. E. e DOMSCH, K. H. The metabolic quotient for $\mathrm{CO}_{2}\left(q \mathrm{CO}_{2}\right)$ as a specific activity parameter to assess the effects of environmental conditions, such as $\mathrm{pH}$ on the microbial biomass of forest soils. Soil Biol.

Biochem., v. 25, p. 393-395. 1993.

BENTO, F. M.; CAMARGO, F. A. O.; OKEKE.

B. Bioremediation of soil contaminated by diesel oil. Brazilian Journal of Microbiology, v.34, p.65-68, 2003.

\section{CANALS, M. V. Biorremediación de suelos contaminados por hidrocarburos: caracterización microbiológica, química y} ecotoxicológica. Facultat de Biologia. Universitat de Barcelona. Barcelona. 352p. 2004.

DIBBLE, J. R. e BARTHA, R. Effect of 
environmental parameters on the biodegradation of oil sludge. Appl. Env. Microbiol.v. 37, p. 729739. 1979.

FRIGHETTO, R. T. S. Análise da biomassa microbiana em carbono: método de fumigaçãoextração. In. Indicadores biológicos e bioquímicos da qualidade do solo. Manual Técnico. EMBRAPA. São Paulo. 2000.

GRISI, B. M.; Metodologia da determinação de biomassa microbiana de solo. Revista Brasileira de Ciências do Solo, v.8, n. 2, p. 167-172. 1984.

JACQUES, R. J. S; BENTO, F. M.; ANTONIOLLI, Z. I.; CAMARGO, F. A. O. Biorremediação de solos contaminados com hidrocarbonetosaromáticos policíclicos. Ciência Rural, v. 37, n. 4, p. 1192-1201. 2007.

MORENO, C. M.; BECERRA, A. G.; SANTOS, M. J. B. Tratamientos biológicos de suelos contaminados: contaminacíon por hidrocarburos. Aplicaciones de hongos em tratamientos de biorecuperacíon. Ver. Iberoam. Micol., v. 21, p. 103-120. Madri. 2004.

PAULA, A. M.; SOARES, R. F. S.; SIQUEIRA, J. O. Biomassa, atividade microbiana e fungos micorrízicos em solo de "landfarming" de resíduos petroquímicos. Rev. Bras. de Eng. Agrícola e Ambiental, v. 10, n.2, p. 448-455, 2006.

VANCE et al. An extraction method for measuring soil microbial biomass C. Soil Biology and Biochemistry, v. 19, p. 703-707, 1987.

STANDARD METHODS FOR THE EXAMINATION OFWATER AND WASTEWATER. 20. ed. 1998. p. 5-39.

ZOBELL, C. E. Studies on redox potential of marine sediments. Bull. Am. Assoc. Petrol. Geologists, v.30, p. 477-509, 1946.

ReCEBIDO EM 23/4/2010

Aсеiтo Eм 23/7/2010 